

\title{
NIOSH Warns of Hazards of Flood Cleanup Work
}

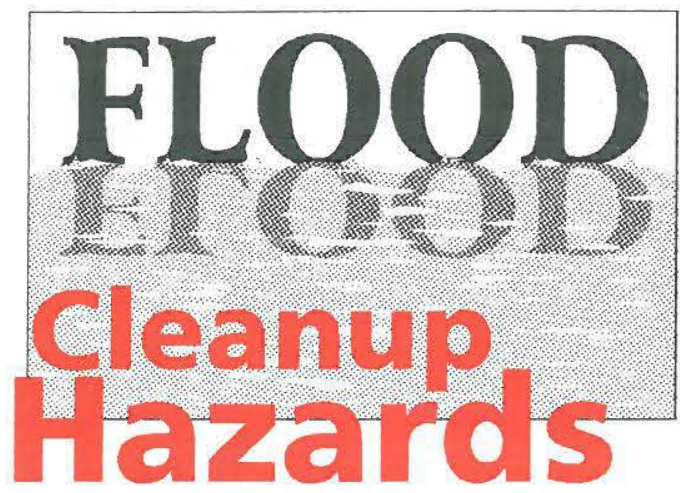

The National Institute for Occupational Safety and Health (NIOSH) warns flood workers that when the seemingly endless rain tapers off and the flood waters recede, they will continue to face a number of hazards associated with cleanup activities.

"Unfortunately the danger of a flood does not end when the rains cease," said NIOSH Director, Dr. Linda Rosenstock. "We must work together to prevent illnesses and injuries that can accompany cleanup efforts," she stressed.

Workers and volunteers involved with flood cleanup should be aware of the potential dangers involved and the proper safety precautions.

Because the level of experience varies among these workers, cleanup crews must work together and look out for one another to ensure safety. NIOSH requests your assistance in disseminating the following warnings to all those involved in flood cleanup. The work-related hazards listed here are described in greater detail on the subsequent pages: Electrical Hazards, Carbon Monoxide, Musculoskeletal Hazards, Thermal Stresses, Heavy Equipment, Structural Instability, Hazardous Materials, Fire, Drowning, Confined Spaces, Power Line Hazards, Agricultural Hazards, Stress and Fatigue.

\section{DANGER Electrical Hazards:}

NIOSH has investigated several work-related electrocution deaths following natural disasters. To prevent future electrocutions, NIOSH urges those involved in cleanup activities to take the following steps:

If water has been present anywhere near electrical circuits and electrical equipment, turn off the power at the main breaker or fuse on the service panel. Do not turn the power back on until electrical equipment has been inspected by a qualified electrician. Never enter flooded areas or touch electrical equipment if the ground is wet, unless you are certain that the power is off. NEVER handle a downed power line.

When using gasoline and diesel generators to supply power to a building, switch the main breaker or fuse on the service panel to the "off" position prior to starting the generator. This will prevent inadvertent energization of power lines from backfeed electrical energy from the generators, and help to protect utility line workers from possible electrocution.

If clearing or other work must be performed near a downed power line, contact the utility company to discuss de-energizing and grounding or shielding of power lines. Extreme caution is necessary when moving ladders and other equipment near overhead power lines to avoid inadvertent contact. If you are working on or near power lines, refer to the additional recommendations provided in the side bar on page three.

U.S. DEPARTMENT OF HEALTH \& HUMAN SERVICES
Public Health Service
Centers for Disease Control and Prevention
National Institute for Occupational Safety and Health

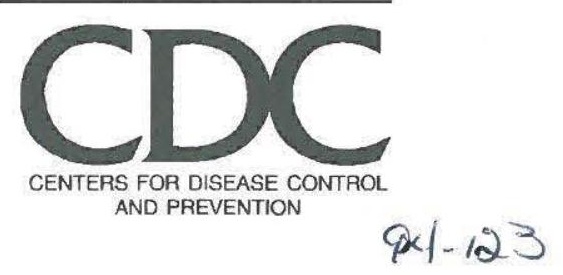




\section{Potential Hazards And Proper Prevention Measures...Continued}

\section{DANGER Carbon Monoxide:}

Flood cleanup activities may involve the use of gasolineor diesel-powered pumps, generators, and pressure washers. Because these devices release carbon monoxide, a deadly, colorless, odorless gas, operate all gasoline-powered devices outdoors and never bring them indoors. It is virtually impossible to assess adequate ventilation. NIOSH has investigated several carbon monoxide poisoning deaths in the past caused by the use of gasoline-powered engines indoors or in confined spaces.

\section{DANGER Musculoskeletal Hazards:}

Cleanup workers are at risk for developing serious musculoskeletal injuries to the hands, back, knees, and shoulders. Special attention is needed to avoid back injuries associated with manual lifting and handling of debris and building materials. To help prevent injury, use teams of two or more to move bulky objects, avoid lifting any material that weighs more than 50 pounds (per person), and use proper automated-assist lifting devices.

\section{DANGER}

\section{Thermal Stresses:}

\section{Heat}

Cleanup workers are at serious risk for developing heat stress. Excessive exposure to hot environments can cause a variety of heat-related problems, including heat stroke, heat exhaustion, heat cramps, and fainting. To reduce the potential for heat stress, drink a glass of fluid every 15 to 20 minutes and wear light-colored, loose- fitting clothing. Additionally, incorporate work-rest cycles into work routines, work during the cooler hours of the day, when possible, or distribute the workload evenly throughout the day. When air conditioning is unavailable, open windows and use fans.

\section{Cold}

Standing or working in water which is cooler than $75^{\circ} \mathrm{F}$ $\left(24^{\circ} \mathrm{C}\right)$ will remove body heat more rapidly than it can be replaced, resulting in hypothermia. To reduce the risk of hypothermia, wear high rubber boots, ensure that clothing and boots have adequate insulation, avoid working alone, take frequent breaks out of the water, and change into dry clothing when possible.

\section{DANGER Heavy Equipment:}

Only those properly trained should operate heavy equipment such as bulldozers, backhoes, and tractors. If you are operating this type of equipment, turn it off and block it against motion prior to dismounting for any reason.
DANGER Structural Instability:

Flood waters can rearrange and damage natural walkways, as well as sidewalks, parking lots, roads, buildings, and open fields. Never assume that water-damaged structures or ground are stable. Buildings that have been submerged or have withstood rushing flood waters may have suffered structural damage and could be dangerous. Don't work in or around any flood-damaged building until it has been examined and certified as safe for work by a registered professional engineer or architect. Assume all stairs, floors, and roofs are unsafe until they are inspected. Leave immediately if shifting or unusual noises signal a possible collapse.

\section{DANGER Hazardous Materials:}

Flood waters can dislodge tanks, drums, pipes, and equipment, which may contain hazardous materials such as pesticides or propane. Do not attempt to move unidentified dislodged containers without first contacting the local fire department or hazardous material team. If working in potentially contaminated areas, avoid skin contact or inhalation of vapors by wearing appropriate protective clothing and respirators. Contact NIOSH for more information on the proper safety equipment. Frequently and thoroughly wash skin areas that may have been exposed to pesticides and other hazardous chemicals.

\section{DANGER Fire:}

Fire can pose a major threat to an already badly damaged flood area for several reasons: inoperative fire protection systems, hampered fire department response, inoperable firefighting water supplies, and flood-damaged fire protection systems. Workers and employers must therefore take extra precautions. At least two fire extinguishers, each with a UL rating of at least $10 \mathrm{~A}$, should be provided at every cleanup job.

\section{DANGER Drowning:}

When entering moving water, you are at risk for drowning, regardless of your ability to swim. Because those in vehicles are at greatest risk of drowning, it is important to comply with all hazard warnings on roadways and to avoid driving vehicles or heavy equipment into water of an unknown depth. NIOSH recommends that you avoid working alone and wear a Coast Guard-approved life jacket when working in or near flood waters. 


\section{Prevention Measures}

\section{FIRST}

AID

First Aid:

First aid, even for minor cuts and burns, is extremely important when exposure to waters potentially contaminated with human, animal, or toxic wastes exists. Immediately clean out all open wounds and cuts with soap and clean water. Most cuts, except minor scratches, sustained during flood cleanup activities will warrant treatment to prevent tetanus. If you are injured, contact a physician to determine the necessary type of treatment.

\section{CAUilON Protective Equipment:}

For most work in flooded areas, you will need the following personal protective equipment: hard hats, goggles, heavy work gloves, and watertight boots with steel toe and insole (not just steel shank). For information on what equipment you need for protection, contact your local OSHA office or NIOSH.

Excessive noise from equipment such as chain saws, backhoes, tractors, pavement breakers, blowers, and dryers may cause ringing in the ears and subsequent hearing damage. If working with any noise that you must shout over to be heard, you should wear earplugs or other hearing protection devices.

\section{Working in Confined Spaces}

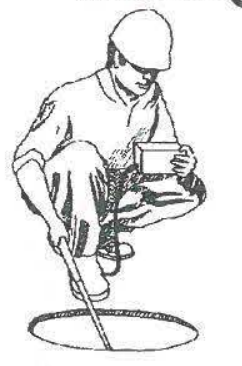

If you are required to work in a boiler, furnace, pipeline, pit, pumping station, septic tank, sewage digester, storage tank, utility vault, well, or similar enclosure, you should be aware of the hazards of working in confined spaces. A confined space has one or more of the following characteristics: (1) limited openings for entry or exit; (2) unfavorable natural ventilation; or (3) is not designed for continuous worker occupancy.

Toxic gases, a lack of oxygen, or explosive conditions may exist in the confined area, resulting in a potentially deadly atmosphere. Because many toxic gases and vapors cannot be seen or smelled, never trust your senses to determine if safe entry is possible. Never enter a confined space unless you have been properly trained, even to rescue a fellow worker! If you need to enter a confined space and do not have the proper training and equipment, contact your local fire department for assistance.

\section{Working On or Near Power Lines}

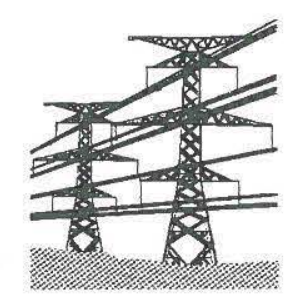

Several workers have died of electrocution following natural disasters. Workers and employers must take extreme caution while attempting to restore power or clear areas near downed power lines. In one instance, a worker lost his life

following Hurricane Hugo after removing trees from a de-energized power line that had been knocked down by the storm. While inspecting the completed work, the man stepped on the line and was electrocuted by "feedback" energy from a portable backup generator at a nearby gas station. Feedback energy occurs when a de-energized line becomes energized by a secondary power source.

A year later, another worker died cleaning branches from a power line, following a tropical storm. He was electrocuted after falling from a tree onto a line thought to be de-energized. Although the workers had opened a fused switch on a transformer, the line remained energized through another transformer.

If you are working on or near power lines, the following steps may save your life:

Treat all power lines as energized until you have followed the required procedures for personally deenergizing and testing them with an appropriate testing device. Do not rely on "fuzzing" to determine if a power line has been de-energized.

Verifying that a line is not energized may not ensure your safety. You must also ground lines on both the load and supply sides of the work area. Grounding is necessary to protect you from the hazards of feedback electrical energy from a secondary power source, such as a portable generator.

When restoring power in underground vaults, added precautions are necessary to avoid explosion hazards. As vaults containing electrical connections are drained or pumped out, and energized, potentially explosive gases may form. If you are required to work in a utility vault, refer to the Confined Spaces section of this Update. 


\section{Potential Hazards And Proper Prevention Measures...Continued}

\section{Agricultural Hazards}

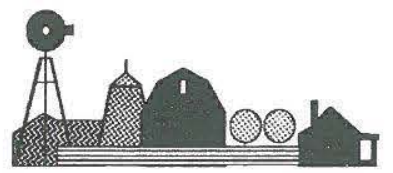

If you are involved in cleanup efforts on or near farms, you may face these additional hazards:

\section{Confined spaces on farms:}

Molding or fermenting agricultural materials in confined spaces may generate large amounts of toxic gases which could cause lung damage or death if inhaled. Turn on fans or blowers in silos and other storage areas at least 30 minutes before entering and leave them on while working. Never open an oxygenlimiting silo if heating is suspected. Also, never enter these areas alone, and always use a full body safety harness.

\section{Respiratory hazards:}

Wet hay, grain, silage, compost, and other organic/agricultural materials often grow large amounts of bacteria and mold during the warm summer weather. Breathing these organisms and the organic dust produced may cause lung disease.

Use proper engineering controls, including adequate fresh air ventilation. When exposure to organic dust cannot be avoided, use NIOSHcertified air-purifying respirators with high efficiency particulate air (HEPA) filters to reduce the risk.

\section{Stored Hay:}

Wet hay will mold very quickly. The biological processes involved in the formation of bacteria and mold can cause the hay to undergo spontaneous combustion. Monitor wet hay for odors, hot and damp areas, and rising vapors. If you detect these hazards, remove the wet hay from the building.

\section{STRESS, LONG HOURS, AND FATIGUE MAY INCREASE THE RISKS FOR INJURY AND ILLNESS}

Continued long hours of work, combined with emotional and physical exhaustion and losses from damaged homes and temporary job layoffs can create a highly stressful situation for flood cleanup workers. Workers exposed to these stressful conditions have an increased risk of injury and emotional crisis, and are more vulnerable to stressinduced illnesses and disease.

Emotional support from family members, neighbors, and local mental health professionals can help to prevent more serious stress-related problems in the difficult months ahead.

People working in all phases of flood cleanup can reduce their risks of injury and illness in several ways:

Set priorities for cleanup tasks and pace the work over several days (or weeks). Avoid physical exhaustion.

Resume a normal sleep schedule as quickly as possible. Get plenty of rest and take frequent rest breaks BEFORE exhaustion builds up.

Take advantage of disaster relief programs and services in your community.

Be alert to emotional exhaustion or strain. When family members and neighbors are unavailable for emotional support, consult professionals at community health and mental health centers.

\author{
For more information about these \\ or other occupational safety and health \\ concerns, call toll free: \\ 1-800-35-NIOSH
}

